\title{
Adsorption of tetracycline by a tailor- made adsorbent in aqueous system
}

\begin{abstract}
Tetracyclines are frequently used antibiotics for growth promotion and therapeutic pharmaceuticals both by humans and animal husbandry, and commonly encountered in municipal wastewater treatment plants and in the environment in their active form. This implies their continuous release into the environment may facilitate toxic effects both on humans and the environment including development of resistance strains, among others. This research was focused on the synthesis, characterisation and assessment of a tailor- made adsorbent: modified chitosan flakes, using several materials for the modification of chitosan to enhance its sorption properties thereby facilitating a higher percentage of TC removal from a synthetic pharmaceutical wastewater. TC adsorption onto the modified chitosan flakes was relatively fast (equilibrium time $=2 \mathrm{~h}$ ). Sorption studies revealed that TC removal by the adsorbent followed pseudo second order kinetics and Freundlich isotherm models. At higher TC input concentration, the amount of TC removed was also higher, this implied the sorption was concentration dependent. Insight into mechanism of sorption revealed cation exchange was an active means of interaction between the adsorbate and adsorbents moieties.
\end{abstract}

Keywords: tetracycline, adsorption, chitosan, gastropod shell, characterisation
Volume 6 Issue I - 2019

\author{
Adelagun Ruth Olubukola Ajoke \\ Department of Chemical Sciences, Federal University, Nigeria
}

Correspondence: Adelagun Ruth Olubukola Ajoke, Department of Chemical Sciences, Federal University, Wukari, Nigeria, Email jemiruth2009@yahoo.com

Received: December 24, 20I8 | Published: February 0I, 2019

\section{Introduction}

Pharmaceuticals are diverse groups of compounds including disinfectants, diagnostics, personal care products and pharmaceutical drugs, administered to prevent, cure and treat diseases and improve health. Tetracyclines are large group of compounds that are derivatives of polycyclic compound napthacene carboxamine, including Tetracycline, Chlortetracycline, Metacycline, etc. Tetracycline is selected in this study because of its frequent prescription and use as an antibiotic by humans and in veterinary medicine for combating parasites and treatment of bacterial transmitted diseases, in husbandry for the acceleration of poultry, swine and cattle production, and in crop production against fungal growth in fruit trees. ${ }^{1}$ Often partially metabolized and adsorbed in the system, a significant portion of the antibiotic is excreted either as conjugates or as the parent compound into the environment (excretion of unmetabolized TCs ranged between $70-90 \% \%^{2,3}$ Also, unused leftover pharmaceuticals are usually disposed casually to sewage or trash bins. ${ }^{4}$ Thus, body metabolisation and excretion, followed by wastewater treatment plants (WWTs) are considered as the major routes of pharmaceuticals to the environment. WWTs are not designed for the removal of these micro pollutants, and are thus released into the environment together with treated wastewater leading to the contamination of receiving water bodies or soil. ${ }^{5,6}$ In the environment, they produce very subtle effects on aquatic and terrestrial organisms; development of drug resistant species, endocrine disruption in living tissues, irreversible changes. ${ }^{1}$ Several toxicological reports have indicated the occurrence and distribution of pharmaceuticals in the sludges and treated water from WWTs (Hirsch et al., 1999), thus indicating the inability and inefficiency of the WWT plants to remove pharmaceuticals from wastewater. ${ }^{7,8}$ Documentations have reported cases of pharmaceuticals in wastewater treatment plants in North America, ${ }^{9} \mathrm{Japan},{ }^{10} \mathrm{Canada}^{11}$ and some European countries. ${ }^{6}$ Consequently, several advanced technologies are being investigated as tertiary treatment options to enhance the efficiency of the WWT plants, including membrane filtration and advance oxidation at bench, pilot and full scale. ${ }^{6,12-14}$ However, these options are been hampered by high cost. Adsorptive treatments have being considered as a suitable appropriate technological option for the removal of pollutants from aqueous system due to its simplicity of operation, and availability of cheap, non- toxic and huge amount potential sorbents. These include clay minerals and soils, chitosan, zeolites, carbon nanotubes, waste materials from industry and agriculture, ${ }^{15-20}$ activated carbon. Biopolymers with high molecular weight compounds in particular polysaccharides such as chitin and its deactivated-derivative, chitosan are highly assessed as biosorbent in wastewater treatment. They possess properties such as biocompatibility, biodegradability, non toxic and excellent adsorption properties. ${ }^{21}$ Low- cost, availability and a structure containing many reactive sites, chitosan provides excellent chelating materials for pollutants. It has drawn particular attention as an effective biosorbent due to its low cost compared to activated carbon and its high contents of amino and hydroxyl functional groups showing high adsorption potential for various organic pollutants. ${ }^{22}$ It is seen as an attractive alternative to other biomaterials because of its physico-chemical characteristics, chemical stability, high reactivity and selectivity towards varied pollutants.

This paper reports the synthesis, characterization and evaluation of a chemically-modified chitosan flakes obtained from chitin for biosorptive treatment of tetracycline contaminated wastewater. Modification of adsorbents (physical or chemical) are usually carried out to enhance the adsorption capacity of the materials either by increasing pore size, porosity, specific surface area, insertion of substituents, decrease/ increase of solubility etc. In this study, chitosan samples obtained via deacetylation of chitin was modified thus: To the chitosan flakes, glutaldehyde was added as crosslinker to enhance its stability in acidic medium; powered gastropod shell was added as a pore-forming agent to increase the porosity of the adsorbent formed, thereby increasing the surface area and diffusion coefficient for mass transfer; ${ }^{23}$ magnetic- inducing particles were added for ease of separation from the aqueous system. The kinetic and isotherms parameters from the time - concentration and sorption studies are also reported. 


\section{Materials and methods}

\section{Materials}

Powdery form of shells of the African land snail (Achatina achatina) was used as the pore- forming agent, whose preparation and characterisation has been well described and reported. ${ }^{24,25}$ Shells of prawns purchased from Malaysia were used to prepare chitosan samples (Figure 1). The deacetylation of the prawn shells was achieved by heating it with $80 \% \mathrm{NaOH}$ solution of ratio $1: 14(\mathrm{w} / \mathrm{v})$ for $6 \mathrm{~h}$ with intermittent stirring for homogenous reaction (Figure 2). The resulting chitosan was washed to neutrality using distilled water, filtered and air-dried. The chitosan sample prepared was tested by dissolving it in $1 \%$ acetic acid. The TC hydrochloride (Figure 1) was purchased from a registered pharmacy and was used as the source of TC without further treatment. Preparation of the magnetite was carried out by adopting a modified Massart method. ${ }^{26,27}$ To a wellmixed solution containing $250 \mathrm{ml}$ of $0.2 \mathrm{M} \mathrm{FeCl}_{3}$ and $250 \mathrm{ml}$ of $1.2 \mathrm{M}$ $\mathrm{FeSO}_{4}$, was added with vigorous stirring, $1.5 \mathrm{M} \mathrm{NH} \mathrm{NH}_{4} \mathrm{OH}$ solution.
The resulting black precipitate was left for 30mins under magnetic stirring to crystallize, then filtered and washed with deoxygenated water until neutral $\mathrm{pH}$ and separated under magnetic decantation and dried in the oven. The prepared sample (magnetite) was tested with a magnetic bar to confirm its magnetic properties. The preparation of the Modified Chitosan Flakes (MCF) was carried out thus: To a $50 \mathrm{~mL}$ of $25 \%$ aqueous acetic acid, $1 \mathrm{~g}$ of chitosan was added and vigorously stirred. To a known amount of magnetite and snail shell powder, $25 \%$ glutaraldehyde solution was added in a round bottom flask followed by vigorous stirring. The mixture was then placed in a water bath and heated for $2 \mathrm{~h}$ at $50^{\circ} \mathrm{C}$. The chitosan solution and contents of the flask were mixed and stirred until a homogenous solution ensued. The resulting solution was then heated at $70^{\circ} \mathrm{C}$ for $6 \mathrm{~h}$, producing a gelatinous precipitate. The gel produced was washed several times with $0.5 \mathrm{M} \mathrm{NaOH}$ solution and distilled water and dried at $70^{\circ} \mathrm{C}$ for $8 \mathrm{~h}$. The dried gel was grinded and sieved, soaked in $0.5 \mathrm{M} \mathrm{HCl}$ to dissolve the snail shell, (whereby bubbles of $\mathrm{CO}_{2}$ were released to create pores in the adsorbent). The adsorbent produced was washed thoroughly with deionized water, dried in the oven and stored.

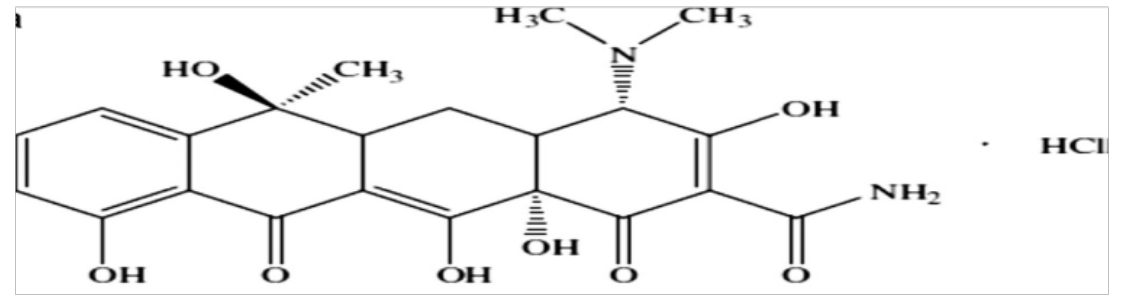

Figure I Structure of Tetracycline Hydrochloride.

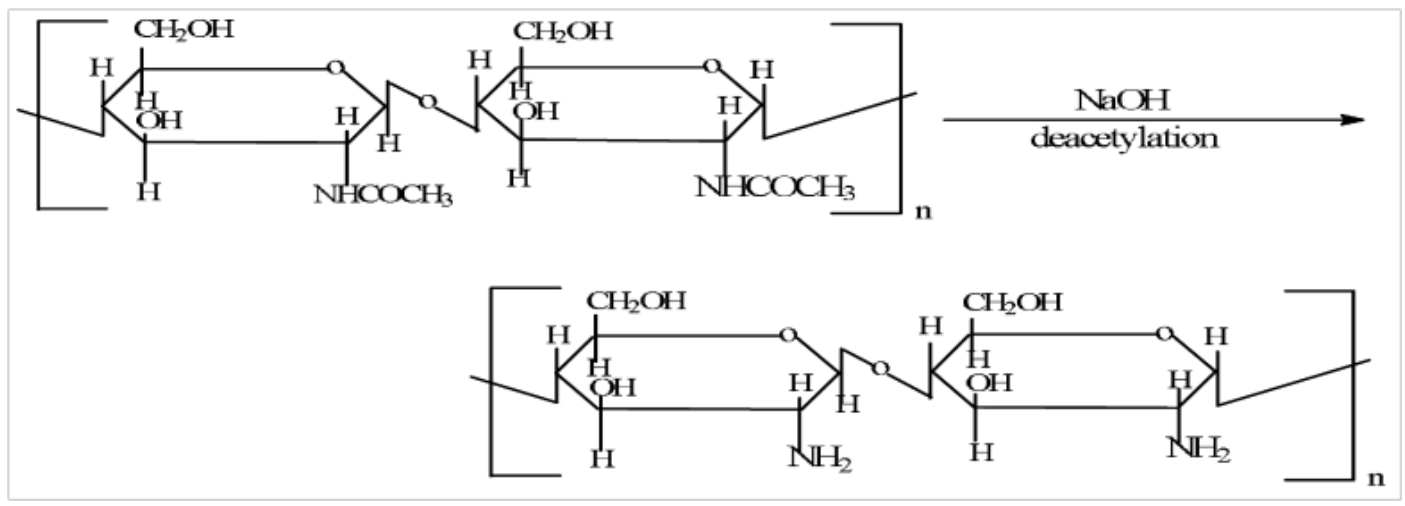

Figure 2 Preparation of Chitosan from Chitin, A Schematic Diagram.

\section{Characterisation}

The functional groups present on the surface of the chitosan flakes (CF) and Modified chitosan Flakes (MCF) samples were examined using Fourier Transform infrared spectrophotometer (FTIR). The porosity $(\varepsilon)$ of the materials was determined using the method described by Chatterjee et al. ${ }^{28} 1 \mathrm{~g}$ of sample was placed in a beaker containing $100 \mathrm{~mL}$ of distilled water and allowed to stay for $24 \mathrm{~h}$. The weight of the wet sample was determined after $24 \mathrm{~h}$ and then dried to constant weight to determine the dried weight. The porosity $(\varepsilon)$ of the material was determined using:

$$
\epsilon=\frac{\frac{\left(W_{w}-W_{D}\right)}{\rho_{w}}}{\frac{w_{D}}{\rho_{\text {mat }}}+\frac{\left(W_{w}-W_{D}\right)}{\rho_{w}}} \times 100 \%
$$

Where, $\mathrm{W}_{\mathrm{W}}(\mathrm{g})$ is the weight of the wet sample before drying; $\mathrm{W}_{\mathrm{D}}$ (g) is the weight of the sample after drying; $p_{w}$ is the density of water and $\rho_{\text {mat }}$ is the density of sample, $\left(\mathrm{g} / \mathrm{cm}^{3}\right)$. The degree of deacetylation of the prepared chitosan samples was calculated by:

$$
D D=100-\frac{A_{1600}{ }^{-1} / A_{3450}-1}{1.33} \times 100
$$

Where, DD is deacetylation degree, $\mathrm{A}_{1660 \mathrm{~cm}}{ }^{-1}$ and $\mathrm{A}_{3450 \mathrm{~cm}}{ }^{-1}$ are absolute heights of absorption band of amide and hydroxyl groups. The degree of swelling of the sample in distilled water was determined by monitoring the weight gain of the sample in the water. The dry sample was immersed in distilled water for $24 \mathrm{~h}$ at room temperature. The degree of swelling ( $\mathrm{Sw}$ ) was calculated as follows:

$$
S_{w}=\frac{W-W_{0}}{W_{0}}
$$


Where, $\mathrm{W}$ and $\mathrm{W}_{0}$ denote the weight of material with absorbed water and the dry material respectively. Moisture content of the prepared chitosan sample was determined using gravimetric method, by drying the sample to constant weight and measuring the weight of sample before and after drying. The difference in the weights gives the moisture content by:

$\%$ moisture content $=\frac{\text { Wet weight }(g-\operatorname{Dry} \text { Weight }(g) \quad x 100}{\text { Wet }_{\text {eight }}(g)}$

Ash content of chitosan samples was determined thus: $2 \mathrm{~g}$ of CF sample was placed into a previously heated and cooled crucible and heated in a muffle furnace preheated to $650^{\circ} \mathrm{C}$ for $4 \mathrm{~h}$. The crucible was allowed to cool in the furnace to less than $200^{\circ} \mathrm{C}$ and then placed in a desiccator. Ash content in the CF sample was determined by:

$$
\% \text { Ash Content }=\frac{(\text { Weight of residue }(g) \times 100}{\text { Sample weight }(g)}
$$

The water-binding capacity (WBC) and fat- binding capacity (FBC) of the prepared chitosan flakes were assessed using a modified procedure described by Wang \& Kinsella $^{29}$ thus: $10 \mathrm{ml}$ of water or soybean oil was added to $0.5 \mathrm{~g}$ of chitosan flakes contained in a weighed $50 \mathrm{ml}$ centrifuge bottle and mixed on a vortex mixer for $1 \mathrm{~min}$ to disperse the sample. The contents were left for $30 \mathrm{~min}$ with shaking for $5 \mathrm{~s}$ every $10 \mathrm{mins}$, followed by centrifuging at $3200 \mathrm{rpm}$ for $25 \mathrm{~min}$. The supernatant was decanted while the tube with the residue weighed again. The WBC or WFC is calculated from the difference in weight. The chemical stability test was carried out in an acidic medium using the procedure described by Khoo \& Ting. ${ }^{30}$ The specific surface areas of the $\mathrm{CF}$ and the MCF samples were determined using a modified method of measuring specific surface based on the theory of the single-layer molecular absorption of methylene blue on a solid surface. Multiplying the value of the saturation adsorption capacity $\left(q_{m}\right)$ derived from a linear plot of the Langmuir equilibrium isotherm equation (see eqn 10) by 2.45 gives the specific surface area of the sample. ${ }^{31}$

\section{Sorption studies}

A stock solution of TC $(2000 \mathrm{mg} / \mathrm{L})$ was prepared with laboratory grade water and working solutions of different TC concentrations $(25-300 \mathrm{mg} / \mathrm{L})$ were prepared from the stock by serial dilution. The equilibrium isotherm analysis of the sorption process was assessed by contacting $50 \mathrm{~mL}$ of TC solution of known concentration $(25-300 \mathrm{mg} / \mathrm{L})$ with $0.1 \mathrm{~g}$ of $\mathrm{MCF}$ and agitated at $200 \mathrm{rpm}$ in a thermostatic shaker for $2 \mathrm{~h}$. Samples were then withdrawn and the sorbent was separated from the reacting mixture with an external magnetic bar. Residual $\mathrm{TC}$ in the supernatant was determined using a UV-spectrophotometer at a wavelength of $276 \mathrm{~nm}$. All of the concentrations considered in this work resulted in absorbance values that were $<2$ and followed Lambert-Beer's law. The kinetic studies of the sorption of TC by MCF was evaluated by contacting $2 \mathrm{~g}$ of MCF with $1 \mathrm{~L}$ TC solution of varying concentrations $(25-200 \mathrm{mg} / \mathrm{L})$. Samples were withdrawn at intervals between 0 and $4 \mathrm{~h}$ of sorption. The amount of TC adsorbed per unit mass of MCF at equilibrium, $\left(q_{e}(\mathrm{mg} / \mathrm{g})\right)$ was calculated by using the mass balance equation (Figure 3 ):

$$
q e=\frac{C_{O}-C_{e}}{w} x V
$$

Where, $c o$ and $c e(\mathrm{mg} / \mathrm{g})$ are the liquid-phase concentrations of TC at initial and final equilibrium, respectively, $v$ and $w$ are volume (ml) of adsorbate and amount ( $\mathrm{g}$ ) of adsorbent used respectively. The TC removal percentage was calculated as follows:
$\%$ TC Removed $=\frac{C_{O}-C_{e}}{C_{o}} \times 100$

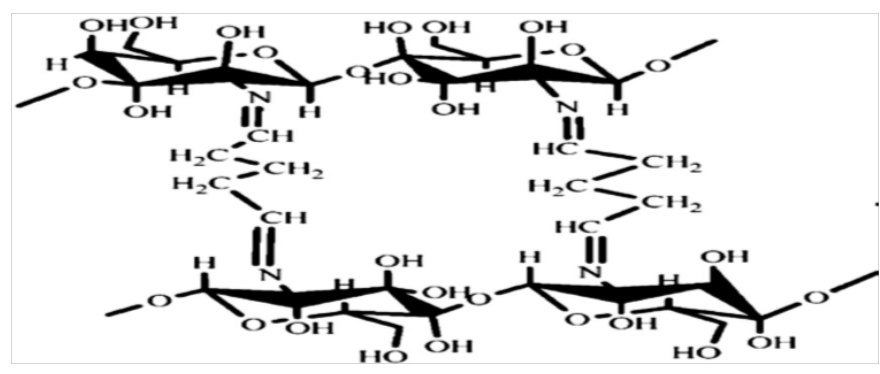

Figure 3 Structure of Chitosan cross-linked with Glutaldehyde.

\section{Results and discussion}

The results of the physicochemical properties of the prepared chitosan flakes given in Table 1 revealed that the chitosan samples prepared from the chitin confirmed to that in reported data. ${ }^{32,33}$ The prepared CF samples have low ash content of $1.19 \%$, an indication of an effective demineralization step for removal of mineral materials. Commercial chitosan has been reported to have ash content of $1.18 \%{ }^{29,33}$ Hossein et al., ${ }^{33}$ reported that the moisture content of chitosan from prawn is in the range of $1.0-1.30 \%$, that obtained from this study was 1.26 . The degree of deacetylation (DD) calculated by using Egn. 2 and FTIR analysis, (Figure 4) was $80 \%$. The value of DD is usually affected by the source and preparation procedure and usually ranges between $30-95 \%{ }^{34}$ The degree of deacetylation of chitin affects the solubility, chemical reactivity and biodegradability of the chitosan obtained from the chitin.

The effect of the addition of the snail shell, the pore forming agent to the chitosan flakes was seen in the increase in the porosity from $21.34 \%$ for $\mathrm{CF}$ to $44.26 \%$ for MCF when soaked in dilute $\mathrm{HCl}$ as was also observed in the specific surface area which was $47.95 \mathrm{~m}^{2} / \mathrm{g}$ for $\mathrm{MCF}$ and $23.98 \mathrm{~m}^{2} / \mathrm{g}$ for CF. Results obtained on the chemical stability of the two samples (CF and $\mathrm{MCF}$ ) indicated a complete dissolution (instability) for CF. MCF, whereas was stable in the acidic medium, however, there was a minimal loss in weight (8\%). This stability of the $\mathrm{MCF}$ in the acidic medium is attributed to the crosslinks inserted in the chitosan structure, which hindered its dissolution in acidic media. While, the loss observed in weight of the MFC in acidic medium could be as a result of the migration of some of its constituents into the acidic medium. The results obtained for the degree of swelling for the two samples indicated that the degree of swelling in the MCF was higher (1.83) than that of the CF (0.82). The higher degree of swelling of the MCF is also attributed to the increase in its porosity, which promotes fluid transfer and the movement of water into it.

The FTIR spectra of the prepared chitosan sample (Figure 4) gave characteristics bands at $3404.37 \mathrm{~cm}^{-1}$ attributed to $-\mathrm{NH}_{2}$ and $-\mathrm{OH}$ groups stretching vibration while the band at $1656.91 \mathrm{~cm}^{-1}$ was attributed to the stretching vibrations of amide group carbonyl bonds in the infrared spectrum of chitosan. ${ }^{28}$ The characteristic carbonyl stretching of chitosan was observed at $1755.28 \mathrm{~cm}^{-1}$. Chitosan absorption peak corresponding to the amine groups were observed at $1558.54 \mathrm{~cm}^{-1} .{ }^{28,35}$ Other notable peaks characteristics of chitosan $\mathrm{C}-\mathrm{H}$ bonds were observed at $2922 \mathrm{~cm}^{-1}, 2877 \mathrm{~cm}^{-1.36}$ Significant differences were detected in the spectra of the modified chitosan flakes MCF (Figure 4) in comparison to that of CF. New peaks were detected 
in the infrared spectra of the MRC that were not in that of the CF sample. Vibration peaks detected at 2856.67 and $1635.69 \mathrm{~cm}^{-1}$ were attributed to the $\mathrm{C}-\mathrm{H}$ stretching of the secondary alcoholic groups and $\mathrm{C}=\mathrm{N}$ stretching of the imine groups, respectively. This suggested the cross-linkage formed between the amine groups in the chitosan and the glutaldehyde (Figure 3) ${ }^{37}$ Also, the intensity as well as the positions of the peaks that were detected in the spectra of CF samples was reduced significantly in the spectra of the MCF. The characteristic absorption band of the $-\mathrm{NH}_{2}$ and $-\mathrm{OH}$ groups at 3404.47 in $\mathrm{CF}$ were shifted to 3441.12 in the MCF. The peak at $1712.85 \mathrm{~cm}^{-1}$ was ascribed to the presence of free aldehyde group, which did not react with amino groups in the raw chitosan.

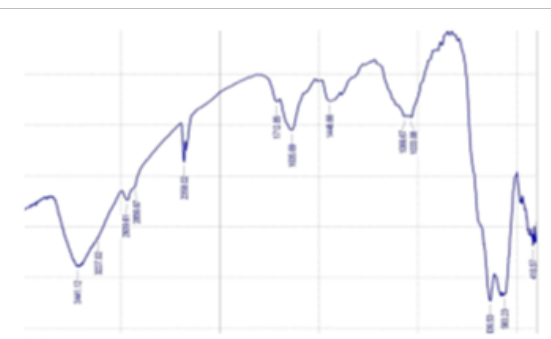

(a)

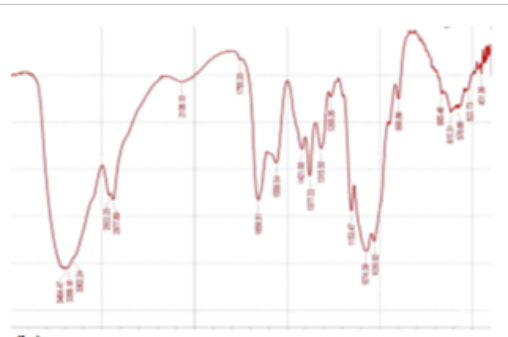

(b)

Figure 4 (a) FTIR Spectra of CF Samples, (b) FTIR Spectra of MCF Samples.

Table I Physicochemical Properties of Chitosan Flakes (CF) Samples

\begin{tabular}{lllllll}
\hline Moisture (\%) & Ash (\%) & DD (\%) & M.Wt (g/mol) & Solubility & WBC (\%) & FBC (\%) \\
\hline 1.26 & 1.19 & 80 & 105 & $1 \%$ Acetic acid & 670 & 420 \\
\hline
\end{tabular}

\section{TC sorption kinetics}

The results of TC sorption by MFC conducted at varying initial $\mathrm{TC}$ concentrations $(25-300 \mathrm{mg} / \mathrm{l})$ for $4 \mathrm{~h}$ revealed that TC removal by $\mathrm{MCF}$ occurred gradually until $2 \mathrm{~h}$ before equilibrium was attained for all initial TC concentrations studied. To derive the sorption kinetic parameters, the experimental data of the time - concentration profiles were tested with different kinetic models. The pseudo second order kinetic model that describes a chemical sorption and cation exchange reaction mechanism of pollutants adsorption from aqueous system ${ }^{38}$ fitted the experimental data best among the kinetic models used with $\mathrm{R}^{2}$ values $>0.99$. The non - linear rate law of the pseudo second order kinetic model is given as:

$$
q e=\frac{k q 2_{e} t}{1+k q_{e} t}
$$

Where, $\mathrm{k}$ is the rate constants of pseudo-second order of adsorption $((\mathrm{g} / \mathrm{mg}) / \mathrm{h}), q e(\mathrm{mg} / \mathrm{g})$ is the amount sorbed at equilibrium on the surface of the MCF. The linear form of Eqn. (8) is

$$
\frac{t}{q_{t}}=\frac{1}{k q 2_{e}}+\frac{1}{q_{e}} t
$$

$k q 2$ is the initial sorption rate $(\mathrm{mg} / \mathrm{g} \mathrm{h})$, is represented by $h$ in Table 2 . The values of the pseudo second order parameters (Table 2) obtained when the kinetic parameters were fitted into Eqn. (9), showed that the amount of TC sorbed by the MCF (qe) increased with an increase in initial TC concentration. The value of $q e$ increased from 4.460 to $16.340 \mathrm{mg} / \mathrm{g}$ as the TC initial concentration was increased from 25 to $300 \mathrm{mg} / \mathrm{L}$. Ho \& McKay $^{39}$ opined that for a sorbate uptake that is chemically rate controlled, the value of $k$ will depend on the concentration of the ions in solution. This statement was depicted in this study. The value of $k$ decreased from 0.077 to $0.044 \mathrm{~g} / \mathrm{mg} \mathrm{h}$ as the initial TC concentration was increased from 25 to $300 \mathrm{mg} / \mathrm{L}$. The values obtained for $h$ also increases from 1.532 to $11.748 \mathrm{mg} / \mathrm{g} \mathrm{h}$, these high values indicated that the MCF is a good adsorbent for TC. ${ }^{40,41}$

\section{TC sorption isotherm}

The adsorption isotherm of TC by MCF at ambient temperature is shown in Figure 5. The result obtained showed that the amount of
TC removed increased with increasing initial TC concentration. This may be attributed to the fact that increase in adsorbate concentration results in increase in number of available molecules per binding sites of the adsorbent thus bringing about a higher possibility of binding of molecules to the adsorbent. Increase in initial TC concentration enhances the interaction between the TC molecules and the surface of the adsorbent. This trend is a common phenomenon in most adsorption studies. ${ }^{42-45}$ The sorption isotherm parameters obtained from the fitting of the experimental data into isotherm models is presented in Table 3. The linearized form of the Langmuir and Freundlich isotherm equations respectively is given respectively, as:

$$
\begin{array}{r}
\frac{c_{e}}{q_{e}}=\frac{1}{q_{m}} c_{e}+\frac{1}{k_{l} q_{m}} \\
\log q_{e}=\frac{1}{n} \log c_{e}+\log k_{f}
\end{array}
$$

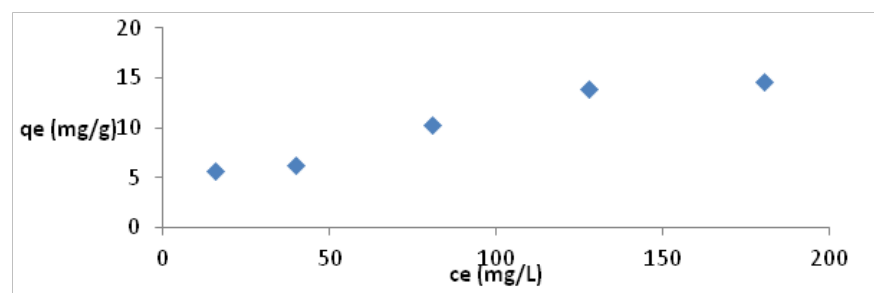

Figure 5 TC Sorption Isotherm.

Where, $k_{L}$ is Langmuir coefficient $(\mathrm{L} / \mathrm{mg}), q m$ is theoretical monolayer sorption capacity $(\mathrm{mg} / \mathrm{g}), q e$ is amount of TC sorbed at equilibrium, ce is equilibrium concentration of TC in solution, $k_{F}$ (L.mg) is Freundlich coefficient, $1 / \mathrm{n}$ is sorption intensity, depicting the affinity of the adsorbate for the adsorbent. To elucidate which of the models gave a better fitting to the experimental data, the correlation coefficients of their linear plots were used. Results obtained (Table 3) indicated that the Freundlich gave a higher $\mathrm{R}^{2}$ value of 0.9914 . The Freundlich isotherm model hints on multilayer sorption on a heterogeneous surface. This implies that the surface of the MCF is heterogeneous, believed to be caused as a results of the different materials used in tits synthesis. Fe- rich materials have been reported to release TC from aqueous system via surface complexation 
mechanisms, ${ }^{46}$ while $\mathrm{Ca}$ - rich materials uses cation exchange as mechanisms of TC removal. ${ }^{47}$

\section{TC energy of sorption}

The determination of the energy of sorption of TC by MCF was assessed by fitting the experimental data obtained from the equilibrium isotherm studies into the Dubinin-Radushkevick isotherm equation. The non linear form of the DR equation is given as:

$$
q e=q m \exp \left(-K \varepsilon^{2}\right)
$$

where, $\varepsilon$ (polanyi potential) is defined as:

$$
\varepsilon=R T\left(1+\frac{1}{c e}\right)
$$

The linear form of $\mathrm{D}-\mathrm{R}$ isotherm is:

$$
\text { lnqe }=\ln q m-\left(K \varepsilon^{2}\right)
$$

$\mathrm{K}$ is related to the mean adsorption energy $\mathrm{E}\left(\mathrm{kJ} \mathrm{mol}^{-1}\right)$ as:

$$
E=\frac{1}{\sqrt{2 \mathrm{~K}}}
$$

The constants $q_{m}(\mathrm{~mol} / \mathrm{g})$ is the D-R constant representing the theoretical saturation capacity and $\varepsilon(\mathrm{mol} / \mathrm{J})$ is a constant, related to the mean free energy of adsorption per mole of the adsorbate, $R$ is the ideal gas constant, $(8.314 \mathrm{~kJ} / \mathrm{mol}), T(\mathrm{~K})$ is the temperature of adsorption and $E(\mathrm{~kJ} / \mathrm{mol})$ is the mean free energy of adsorption per molecule of the adsorbate when transferred to the surface of the solid from infinity in solution. ${ }^{45,47}$ The plot of $\ln q_{e}$ against $\varepsilon^{2}$ was used to obtain the constants $q_{m}$ and $k$, calculated from the intercept and slope respectively. Results obtained indicated that $q m$ is $11.62 \mathrm{~mol} / \mathrm{gm}$ and $\varepsilon^{2}$ is 0.00005 and $E$ is $100 \mathrm{x} 10^{6} \mathrm{~kJ} / \mathrm{mol}$. The magnitude of $E$ is used to determine and classify the type of sorption reaction, whether chemisorption or physisorption. For a physisorption reaction, the value of $E$ is between $1-16 \mathrm{~kJ} / \mathrm{mol}$, reactions with $E$ values higher than $16 \mathrm{~kJ} / \mathrm{mol}$ is termed chemisorptions. ${ }^{47-49}$ The value of $E$ obtained for the sorption of TC by MCF is by far higher than $16 \mathrm{~kJ} / \mathrm{mol}$ and this is an indication that the mechanism of interaction between TC and MCF is chemisorption. This further confirms the results from kinetic studies in which pseudo second order kinetic model prevailed.

Table 2 Pseudo Second Order Kinetics Parameters of TC Sorption by MCF Samples

\begin{tabular}{llllll}
\hline Initial conc $(\mathbf{m g} / \mathbf{L})$ & Relationship $(\mathbf{y}=$ & $\mathbf{R}^{2}$ & $\mathbf{q e}(\mathbf{m g} / \mathbf{g})$ & $\mathbf{k}(\mathbf{g} / \mathbf{m g} \mathbf{~})$ & $\mathbf{h}(\mathbf{m g} / \mathbf{g ~ h})$ \\
\hline 25 & $0.224 x+2.926$ & 0.996 & 4.460 & 0.077 & 1.532 \\
50 & $0.136 x+2.291$ & 0.9997 & 7.305 & 0.060 & 3.202 \\
100 & $0.094 x+2.751$ & 0.9917 & 10.549 & 0.034 & 3.784 \\
150 & $0.660 x+1.878$ & 0.9916 & 15.083 & 0.035 & 7.962 \\
200 & $0.061 x+1.402$ & 0.9977 & 16.340 & 0.044 & 11.748
\end{tabular}

Table 3 Equilibrium Isotherm Parameters for the Removal of TC

\begin{tabular}{ll}
\hline Langmuir Isotherm & Freundlich \\
\hline $\mathrm{qm}=23.81$ & $\mathrm{n}=1.872$ \\
$\mathrm{k}_{1}=0.0131$ & $\mathrm{k}_{\mathrm{F}}=1.010$ \\
$\mathrm{r}^{2}=0.963$ & ${ }^{\mathrm{r} 2}=0.9916$ \\
\hline
\end{tabular}

\section{Conclusion}

From the results obtained in this study, the following conclusion can be drawn:

1. Preparation of chitosan from chitin and synthesis of an efficient adsorbent (MCF) for TC removal from aqueous system was possible.

2. Adsorption of TC on the adsorbent MCF followed pseudo-second order kinetics and equilibrium was attained relatively quickly (2h).

3. The mode of interaction between the TC and MCF moieties in solution was via cation exchange.

4. Adsorption of TC on MCF followed Freundlich adsorption isotherm with a monolayer adsorption capacity of $23.81 \mathrm{mg} / \mathrm{g}$

5. Estimation of energy of TC sorption indicated chemisorption as the dominant mechanism

\section{Acknowledgments}

None

\section{Conflicts of interest}

The author declares there are no conflicts of interest.

\section{References}

1. Le-Minh N, Khan SJ, Drewes JE, et al. Fate of antibiotics during municipal water recycling treatment processes. Water Res. 2010;44(15):4295-4323.

2. Halling-Sørensen B. Algal toxicity of antibacterial agents used in intensive farming. Chemosphere. 2000;40(7):731-739.

3. Jjemba PK. The potential impact of veterinary and human therapeutic agents in manure and biosolids on plants grown onarable land: a review. Ecosyst Environ. 2002;1918:1-12.

4. Daughton CG, Jones-Lepp T. Pharmaceuticals and Personal Care Products in the Environment: Scientific and Regulatory Issues. ACS Symposium Series 791; American Chemical Society: Washington DC; 2001 .

5. Castiglioni S, Bagnati R, Fanelli R, et al. Removal of pharmaceuticals in sewage treatment plants in Italy. Environmental Science and Technology. 2006;40(1):357-363.

6. Vieno N, Tuhkanen T, Kronberg L. Elimination of pharmaceuticals in sewage treatment plants in Finland. Water Research. 2007;41(5):10011012.

7. Othersen OG, Beierlein F, Lanig H, et al. Conformations and Tautomers of Tetracycline. J Phys Chem B. 2003;107(49):1.

8. Blake DP, Humphry RW, Scott KP, et al. Influence of tetracycline exposure on tetracycline resistance and the carriage of tetracycline 
resistance genes within commensal Escherichia coli populations. $J$ Appl Microbiol. 2003;94(6):1087-1097.

9. Lishman L, Smyth SA, Sarafin K, et al. Occurrence and reductions of pharmaceuticals and personal care products and estrogens by municipal wastewater treatment plants in Ontario, Canada. Sci Total Environ. 2006;31;367(2-3):544-558.

10. Nakada N, Shinohara H, Murata A, et al. Removal of selected pharmaceuticals and personal care products ( $\mathrm{PPCPs}$ ) and endocrinedisrupting chemicals (EDCs) during sand filtration and ozonation at a municipal sewage treatment plant. Water Res. 2007;41(19):4373-4382.

11. Boussu K, Kindts C, Vandecasteele C, et al. Surfactant fouling of nanofiltration membranes: measurements and mechanisms. Chemphyschem. 2007;24;8(12):1836-1845.

12. Adams C, Wang Y, Loftin K, et al. Removal of antibiotics from surface and distilled water in conventional water treatment processes. Journal of Environmental Engineering e ASCE. 2002;128(3):253-260.

13. Baumgarten S, Schröder HF, Charwath $\mathrm{C}$, et al. Evaluation of advanced treatment technologies for the elimination of pharmaceutical compounds. Wat Sci and Tech. 2007;56(5)1-8.

14. Nghiem LD, Vogel D, Khan S. Characterising humic acid fouling of nanofiltration membranes using bisphenol $\mathrm{A}$ as a molecular indicator. Water Res. 2008;43(4):863-881.

15. Hamscher G, Sczesny S, Höper H, et al. Determination of persistent tetracycline residues in soil fertilized with liquid manure by highperformance liquid chromatography with electrospray ionization tandem mass spectrometry. Anal Chme. 2002;74(7):1509-1518.

16. Meshko V, Markovska L, Mincheva M, et al. Adsorption of basic dyes on granular activated carbon and natural zeolite. Water Res. 2001;35(14):3357-3366.

17. Choi KJ, Kim SG, Kim SH. Removal of tetracycline and sulfonamides classes of antibiotic compounds by powdered activated carbon. Environ Technol. 2008;29(3):333-342.

18. Sassman SA, Lee LS. Sorption of three tetracyclines by several soils: assessing the role of pH and cation exchange. Environ. 2005;7452-7459

19. Ji LL, Chen W, Zheng SR, et al. Adsorption of sulfonamide antibiotics to mutiwalled carbon nanotubes. Langmuir. 2009;25:11608-11613.

20. Li Zhaohui , Chang Hsiang -Po, Jiin -Shuh Jean, et al. Interaction between tetracycline and smectite in aqueous solution. Journal of colloid and interface science. 2010;341:311-319.

21. Crini G, Non-conventional low-cost adsorbents for dye removal: review. Bioresour Technol. 2006;97:1061-1085.

22. ALPF Caroni, CRM de Lima, MR Pereira, et al. The kinetics of adsorption of tetracycline on chitosan particles. J Colloid Interface Sci. 2009;340:182-191

23. Almeida RV, Branco RV, Peixoto $\mathrm{CD}$, et al. Immobilization of a recombinant thermostable esterase (Pf2001) from Pyrococcus furiosus on microporous polypropylene: Isotherms, hyperactivation and purification. Biochem Eng J. 2008;39:531-537.

24. Oladoja NA, Aliu YD. Snail shell as coagulant aid in the alum precipitation of malachite green from aqua system. $J$ Hazard Mater. 2009; 164:1494-1502.

25. Oladoja NA, Aliu YD, Ofomaja AE. Evaluation of snail shell as a coagulant aid in the alum precipitation of aniline blue from aqueous solution. 2011;32(6):639-652.

26. Sun YK, Ma M, Zhang Y, et al. Synthesis of nanometer-size maghemite particles from magnetite. Colloids Surf A. 2004;245:15-19.
27. Donia AM, Atia AA, Elwakeel KZ. Selective separation of mercury(II) using magnetic chitosan resin modified with Schiff's base derived from thiourea and glutaraldehyde. J Hazard Mater. 2008; 151:372-379.

28. Chatterjee S, Lee DS, Lee MW, et al. Nitrate removal from aqueous solutions by cross-linked chitosan beads conditioned with sodium bisulfate. J Hazard Mater. 2009;166:508-513.

29. Wang JC, Kinsella JE. Functional Properties Of Novel Proteins: Alfalfa Leaf Protein J Food Sci. 196;41:286-292.

30. Khoo K, Ting Y. Biosorption of gold by immobilized fungal biomass. Biochem Eng J. 2001;1:51-59.

31. Hang PT. Methylene blue absorption by clay minerals. Determination of surface areas and cation exchange capacities (Clay-Organic Studies XVIII). Clays Clay Miner. 1970;18:203-212.

32. Terbojevudith M, Cosani A. Molecular weight determination of chitin and chitosan. chitin handbook. In: Muzzarelli RAA, Peter MG, editors. European Chitin Society. 1997;1:87-101.

33. Hossein T, Mehran M, Seyed MRR, et al. Preparation of Chitosan from Brine Shrimp (Artemia urmiana) Cyst Shells and Effects of Different Chemical Processing Sequences on the Physicochemical and Functional Properties of the Product. Molecules. 2008;13:1263-1274.

34. Martino A, Turner A, Millward GE. Influence of Organic Complexation on the Adsorption Kinetics of Nickel in River Waters. Environ Sci Techno. 2003;37(11):2383-2388.

35. Marchessault RH, Ravenelle F, Zhu XX. Polysaccharides for drug delivery and pharmaceutical applications. Am Chem Soc. 2006;934:1.

36. Wang T, Turhan M, Gunasekaran S. Selected properties of $\mathrm{pH} \square$ sensitive, biodegradable chitosan-poly(vinyl alcohol) hydrogel. Polym Int. 2004;3:911-918.

37. Anirudhan TS, Rijith S, Glutaraldehyde cross-linked epoxyaminated chitosan as an adsorbent for the removal and recovery of copper(II) from aqueous media. Colloids Surf A. 2009;351:52-59.

38. Ho YS. Review of second-order models for adsorption systems. $J$ Hazard Mat. 2006;36(3):681:689.

39. YS Ho, Mckay G, Chem Sorption of dye from aqueous solution by peat. En J. 1998;70:115-124.

40. Kulshrestha P, Giese Jr RF, Aga DS. Investigating the molecular interactions of oxytetracycline in clay and organic matter: insights on factors affecting its mobility in soil. Environ Sci Technol. 2004;38(15):4097-4105.

41. Li Z, Chang PH, Jean JS, et al. Interaction between tetracycline and smectite in aqueous solution. J Colloid Interface Sci. 2010;341(2):311319.

42. Ofomaja EA, Unuabonah IE, Oladoja NA. Removal of lead from aqueous solution by palm kernel fiber. S Afr J Chem. 2005;58:1-4.

43. Hafez H. A study on the use of nana/ micro structured goethite and heamatite as adsorbents for the removal of $\mathrm{Cr}, \mathrm{Co}, \mathrm{Cu}, \mathrm{Ni}$ and $\mathrm{Zn}$ metal ions from aqueous solutions. J Eng Sc. 2012;4(6):3018-3028.

44. Figueroa RA, Leonard A, Mackay AA. Modeling Tetracycline Antibiotic Sorption to Clays. Environ Sci Technol. 2004;38(2):476-483.

45. Adelagum ROA, Itodo AU, Berezi EP, et al. Adsorptive Removal of $\mathrm{Cd}^{2}+$ and $\mathrm{Zn}^{2}+$ From Aqueous System by BSG. J Chem and Mat Res. 2014;104-112.

46. Pils JRV, Laird DA. Sorption of Tetracycline and Chlortetracycline on K- and Ca-Saturated Soil Clays, Humic Substances, and Clay-Humic Complexes. Environ Sci Technol. 2007;41:1928. 
47. El-Kamash AM, Zaki AA, El Geleel MA. Modeling batch kinetics and thermodynamics of zinc and cadmium ions removal from waste solutions using synthetic zeolite A.J Hazard Mater. 2005;127:211-220.

48. Akkaya G, Ozer A. Process Biochem Sci Technol. 2005;1:3559-3568.
49. Krishna BS, Murty DSR, Jai Prakash BS. Thermodynamics of Chromium(VI) Anionic Species Sorption onto Surfactant-Modified Montmorillonite Clay. J Colloid Interface Sci. 2000;229:230-236. 